\title{
Helicobacter pylori and Epstein-Barr Virus Infection in Gastric Diseases: Correlation with IL-10 and IL1RN Polymorphism
}

\author{
Fasciana Teresa $\mathbb{D}^{1,},{ }^{1,2}$ Nicola Serra $\left(\mathbb{D},{ }^{3}\right.$ Giuseppina Capra, ${ }^{1}$ Chiara Mascarella, ${ }^{1}$ \\ Cesare Gagliardi, ${ }^{3}$ Paola Di Carlo ${ }^{D},{ }^{1}$ Sara Cannella, ${ }^{1}$ Maria Rosa Simonte, ${ }^{1}$ Dario Lipari, ${ }^{1}$ \\ Miriam Sciortino, ${ }^{1}$ Letizia Scola, ${ }^{4}$ and Anna Giammanco ${ }^{1}$ \\ ${ }^{1}$ Department of Health Promotion, Mother and Child Care, Internal Medicine and Medical Specialties "G. D'Alessandro", \\ University of Palermo, Palermo, Italy \\ ${ }^{2}$ Department of Surgical, Oncological and Oral Sciences, Doctoral Program in Oncology and Experimental Surgery, \\ University of Palermo, Palermo, Italy \\ ${ }^{3}$ Department of Public Health, University Federico II of Naples, Naples, Italy \\ ${ }^{4}$ Department of Biomedicine, Neuroscience and Advanced Diagnostics, University of Palermo, Palermo, Italy \\ Correspondence should be addressed to Fasciana Teresa; teresa.fasciana@virgilio.it
}

Received 12 March 2019; Revised 10 July 2019; Accepted 18 August 2019; Published 6 December 2019

Academic Editor: Thomas R. Chauncey

Copyright (c) 2019 Fasciana Teresa et al. This is an open access article distributed under the Creative Commons Attribution License, which permits unrestricted use, distribution, and reproduction in any medium, provided the original work is properly cited.

\begin{abstract}
Introduction. Helicobacter pylori and Epstein-Barr virus (EBV) infection have recently been shown to be associated with gastric diseases. Polymorphisms in genes encoding cytokines such as interleukin 10 (IL-10) and interleukin 1 Receptor (IL-1RN) influence cytokine secretion levels and appear to contribute to the risk of developing gastroduodenal diseases. To our knowledge, this is the first preliminary study to address the association of coinfection with $H$. pylori and EBV and their correlation with genetic predisposition in the development of gastric diseases. Methods. Gastric biopsy samples of 96 patients with different gastric diseases were used. Results. Our results showed that the rate of coinfection was higher in patients with gastric cancer than in patients with normal gastric mucosa, active chronic gastritis, and MALT lymphoma. As regards the characterization of $H$. pilory strains, the polymorphism s1m1i1 of $v a c A$ gene was more frequent in patients with MALT Lymphoma in comparison to others, while the polymorphism $s 2 m 2 i 2$ was most frequent in patients with normal gastric mucosa. In addition, patients who tested positive for the cagA gene were more frequently those affected with gastric cancer than those with inactive chronic gastritis. Similarly, the patients with oipA gene $\mathrm{ON}$ were more frequently those with gastric cancer than those with inactive chronic gastritis. Conclusion. According to our analysis, there was no correlation between coinfection and polymorphisms in genes encoding IL-10 and IL-1RN. We conclude that various factors can be involved in the development of gastric diseases.
\end{abstract}

\section{Introduction}

Gastrointestinal diseases and gastric cancer (GC) are among the most common pathologies worldwide [1]. In recent years, Helicobacter pylori and EBV infection seem to be strongly associated with the development of gastric diseases $[2,3]$.

$H$. pylori, a bacterium that colonizes the gastric mucosa of more than $50 \%$ of the world's population, is considered to be a group 1 carcinogen by the International Agency for Research on cancer [4].
Various virulence factors are involved in the development of gastric diseases in $H$. pylori positive patients; among these, the genes cagA, vacA, and oip $A$ have an important role [5]. The cytotoxicity-associated gene $\mathrm{A}(\operatorname{cag} A)$ is one of the most significant virulence factors of $H$. pylori. It is associated with the development of peptic ulcers and gastric cancer [6]. The vacA gene encoding for VacA protein is capable of inducing large host cell vacuoles in the cytoplasm of gastric cells [7], while the oipA (outer inflammatory protein) gene encodes one of the outer-membrane proteins that contribute 
to gastric inflammation, inducing IL- 8 secretion by epithelial cells [8].

OipA expression is predicted to be regulated by a slipped strand mispairing system based on the number of CT dinucleotide repeats in the $5^{\prime}$ signal peptide coding region of the gene, with "ON" meaning oipA is functional and "OFF" nonfunctional. OipA functional status is involved in bacterial adherence to gastric epithelial cells and in mucosal inflammation.

Treatment failure in $H$. pylori infections is the current issue for physicians. There are many reasons for treatment failure. These can be grouped into microorganism-related factors, host-related factors, and treatment-related factors. $H$. pylori resistance to antibiotics is widely recognized as the chief reason for treatment failure.

H. pylori resistance to clarithromycin has been correlated to point mutations in the peptidyl transferase region of domain $\mathrm{V}$ of the $23 S \mathrm{rRNA}$. The most common mutation is an A-to-G transition at position 2143 (A2143G) and at position 2142 (A2143G).

EBV infection is present in more than $90 \%$ of the population. Upon infection, the virus rests latent in B lymphocytes throughout the person's lifetime [9].

Moreover, the association of EBV with gastric carcinoma was reported for a case of lymphoepithelial-like gastric carcinoma, but the mechanism used by the virus to determine the oncogenesis is still unknown [10].

It seems that EBV deregulation of the expression of immune response-related genes promotes marked intra or peritumoral immune cell infiltration [11]. The relationship of $H$. pylori with early inflammatory precancerous lesions is well known.

However, only a few studies have evaluated the participation of EBV infection in these lesions.

Some studies have found evidence that EBV infects epithelial cells of the atrophic gastric mucosa with a relatively low frequency [12], whereas other studies favour higher frequencies [13].

While both micro-organisms are responsible for the most common infections worldwide, a small percentage of infected patients will develop severe disease [14].

The outcome of the infection depends on the relationship between environment, host, and bacterial virulence factors $[15,16]$. Recently, the polymorphism of proinflammatory cytokines such as IL1RN and anti-inflammatory cytokines such as IL-10 has been implicated in clarifying host factors in the development of gastric diseases [17].

In particular, IL1RN genotypes and low IL-10 production have been associated with an increased risk for severe gastric lesions in patients infected with both microorganisms [18].

In this preliminary study, we analyze $H$. pylori and EBV coinfection and correlation with host genetic variability in gastric tissues from adult patients with different gastric diseases in Italy.

In this study, we considered four groups of patients: group with normal gastric mucosa (control group), group with active chronic gastritis, group gastric MALT (MucosaAssociated Lymphoid Tissue) lymphoma, and group with gastric cancer. These groups were defined considering both premalignant disease and most common malignant disease correlated to micro-organisms such as MALT lymphoma and gastric cancer. The use of the groups was introduced to individualize the impact of each disease singularly and consequently to reduce possible statistical biases.

The investigation was deemed to be of interest as Sicily has one of the most complex mixed ethnic populations in Europe due to its geographical position.

\section{Materials and Methods}

2.1. Patients and Sample Collection. This study was performed on a sample of 96 patients, $34.38 \%$ males, and $65.62 \%$ females, aged 20-87 years, mean 58.27 y.o. and standard deviation (SD) 16.26 y.o.

\subsection{We Considered Four Groups of 24 Consecutive Patients}

(i) Group with normal gastric mucosa (Group NGM), composed of $33.33 \%$ males and $66.67 \%$ females, aged 22-71 years, mean 46.58 y.o. and standard deviation (SD) 14.74 y.o

(ii) Group with active chronic gastritis (Group GCA) composed of $37.50 \%$ males and $62.50 \%$ females, aged 20-87 years, mean 49.04 y.o. and standard deviation (SD) 16.83 y.o

(iii) Group with gastric cancer (Group KG), composed of $33.33 \%$ males and $66.67 \%$ females, aged $55-$ 87 years, mean 69.88 y.o. and standard deviation (SD) 8.68 y.o

(iv) Group with gastric MALT lymphoma (Group ML), composed of $33.33 \%$ males and $66.67 \%$ females, aged 57-80years, mean 67.58y.o. and standard deviation (SD) 6.24 y.o

Exclusion criteria were as follows: previous attempts to eradicate $H$. pylori and use of antibiotics or proton pump inhibitor within 2 weeks prior to endoscopy.

Each patient signed an informed consent form before undergoing endoscopy.

2.3. Sample Collection and Histological Analysis. Gastric biopsy samples were obtained from patients attending the endoscopy ward of the Endoscopy Services of the A.O.U.P. Paolo Giaccone (Palermo, Italy) and M. Raimondi Hospital, San Cataldo (Caltanissetta, Italy). Two biopsy samples were obtained from de the antrum and two from the gastric corpus. One was used for $H$. pylori culture and the second for histologic examination.

In patients suspected of having gastric cancer and MALT lymphoma, samples were taken directly from the gastric lesion.

One antrum sample and one corpus sample was fixed in formaline, paraffin-embedded, and stained with hematoxylin and eosin (HE). Inflammatory response was graded according to the Sydney System by a single experienced pathologist. 
2.4. DNA Isolation from Gastric Biopsies, $H$. pylori, and EBV DNA Detection by PCR Methodology. DNA from the biopsy samples was extracted using a High Pure Template Preparation kit (Roche), in accordance with the manufacturer's instructions. The extracted DNA was stored at $-20^{\circ} \mathrm{C}$ until use.

H. pylori infection was diagnosed when the ureaseA gene was detected with nested PCR, while the BAMHI-W fragment region of the EBV genome was used as the target to evaluate the presence of the virus, according to Di Carlo et al. [19] and Giardina et al. [20].

2.5. Detection of cagA, the EPIYA Motif, Typing of vacA Alleles, and Determining oipA Status. In order to detect the presence of the cagA gene and to analyse the EPIYA motif, the DNA from each strain was subjected to PCR, as described by Panayotopoulou et al. [21]. In determining the EPIYA motif, three different PCR products were obtained: EPIYA ABC (550 bp), EPIYA ABCC (650 bp), and EPIYA ABCCC (750 bp). The signal peptide (s) and midregion $(\mathrm{m})$ of the vacA gene were amplified using the primers described by Atherton et al. [22]. Four different PCR products were obtained: $s 1$ (259 bp) and $s 2(286 \mathrm{bp})$ from the $s$-region and $m 1(290 \mathrm{bp})$ and $m 2$ (352 bp) from the $m$-region (Atherton et al., 1995). Two different PCR products were obtained from the $i$-region: $i 1$ (250 bp) and i2 (260 bp) [23]. OipA status was determined in all strains by PCR and sequencing of the signal region of the oipA gene, according to Yamaoka et al. [24].

2.6. Determination of Point Mutations in the H. pylori $23 S$ rRNA Gene. In order to detect mutations related to clarithromycin resistance in the $23 S r R N A$ gene and to establish the number of CT repeats present in oipA, the same primers used for the amplification gene were employed.

The resulting PCR products were subjected to gel electrophoresis in a $2 \%$ agarose gel, subsequently purified and concentrated for sequencing using Amicon Ultra $0.5 \mathrm{ml}$ columns (Millipore). Purified amplicons were sequenced directly with the same forward and reverse primers used in the previous PCR, using an ABI PRISM BigDye Cycle Sequencing Ready Reaction kit (Applied Biosystems) according to the instructions supplied by the manufacturer. The analysis of products was performed using BioEdit v. 7.2.0 software according to Chiarini et al. [25] and Fasciana et al. [26].

2.7. Genotyping of Cytokine Polymorphisms. The IL-1RN exon 2 polymorphism was analyzed according to Rad et al. [27] Conditions were as follows: $95^{\circ} \mathrm{C}$ for $5 \mathrm{~min}$, then 35 cycles of $95^{\circ} \mathrm{C}$ for $30 \mathrm{~s}, 50^{\circ} \mathrm{C}$ for $30 \mathrm{~s}, 72^{\circ} \mathrm{C}$ for $30 \mathrm{~s}$, and finally $72^{\circ} \mathrm{C}$ for $5 \mathrm{~min}$. The PCR products were analyzed by electrophoresis on a $2 \%$ agarose gel stained with ethidium bromide. Allele 1 ( 4 repeats) was $410 \mathrm{bp}$, allele 2 (2 repeats) was $240 \mathrm{bp}$, allele 3 ( 5 repeats) was $500 \mathrm{bp}$, allele 4 (3 repeats) was $325 \mathrm{bp}$, and allele 5 (6 repeats) was $595 \mathrm{bp}$ in length, according to Forte et al. [28]. Amplification Refractory
Mutation System (ARMS-PCR) was used to type 819C/Tand 1082G/A IL-10 SNP, as described by Crivello et al. [30].

\section{Statistical Analysis}

Data are presented as number and percentage for categorical variables, and continuous data are expressed as mean\pm standard deviation (SD), unless otherwise specified. The multiple comparison chi-square test was used to define significant differences among percentages: if chi-square test was positive $(p$ value $<0.05)$, then residual analysis with the $Z$-test to locate the highest or lowest significant presence was performed. To evaluate significant differences of means among groups, we performed the multicomparison ANOVA test. When the ANOVA test was positive ( $p$ value $<0.05$ ), pairwise comparisons were performed with Scheffe's test.

Univariate and multivariate linear correlation analysis was performed, where the test on Pearson's linear correlation coefficient $R$ was performed with $t$-Student test, under null hypothesis of Pearson's linear correlation coefficient $R=0$. In this step for dichotomies, we defined the experimental probability distribution for the variables Gender, $H p$, $E B V$, and Coinfected, assigning them the following values:

(i) For Gender, male $=1$ and female $=0$

(ii) $\mathrm{Hp}$, presence $=1$ and absence $=0$

(iii) $\mathrm{EBV}$ virus, presence $=1$ and absence $=0$

(iv) Coinfected (patients with HP and EBV virus), yes $=1$, and no $=0$

For polymorphism variables vacA, IL-1RN, and IL-10, we defined, according to the frequency of the variable's modalities in our total sample data, the following scales, respectively:

(i) $s 2 m 2 i 2=5, s 1 m 1 i 1=4, s 1 m 2 i 1=3, s 1 m 2 i 2=2$, and $s 1 m 1-m 2 i 1=1$ and polymorphism absence $=0$

(ii) $1 / 1=5,1 / 2=4,2 / 2=3,1 / 3=2$, and $4 / 4=1$ and polymorphism absence $=0$

(iii) $\mathrm{AA}=3, \mathrm{AG}=2$, and $\mathrm{GG}=1$ and polymorphism absence $=0$

For the gastric disease variables, we used the following scale:

(i) $\mathrm{NGM}=1, \mathrm{GCA}=2, \mathrm{ML}=3$, and $\mathrm{KG}=4$.

We considered all statistical tests with $p$ value $<0.05$ to be significant. All data were analyzed with Matlab statistical toolbox version 2008 (MathWorks, Natick, MA, USA) for 32 bit Windows.

\section{Results and Discussions}

In this preliminary study, we evaluated the relationship between $H$. pylori and EBV infection, and cytokine polymorphism in gastric diseases in people living in the Mediterranean area $[26,30]$. In our study, the positivity rate of $H$. pylori in patients with gastric cancer was higher than that found in patients with normal gastric mucosa, active chronic 
gastritis, and MALT lymphoma, namely, 50\%, 45.83\%, $41.67 \%$, and $45.83 \%$, respectively.

EBV was detected in $54.17 \%$ of the patients with gastric cancer. It was detected in smaller percentages in patients with normal gastric mucosa, active chronic gastritis, and MALT lymphoma, namely, $20.83 \%, 41.67 \%$, and $37.50 \%$, respectively. In any case, the rate of $H$. pylori in all patients analyzed was $45.83 \%$, and the rate of EBV was $38.54 \%$.

The rate of coinfection was higher in patients with gastric cancer than that in patients with normal gastric mucosa, active chronic gastritis, and MALT lymphoma, namely, $37.50 \%, 16.67 \%, 29.17 \%$, and $25 \%$, respectively. The cagA and $v a c A$ genes are commonly used as markers to characterize $H$. pylori virulence. Several epidemiological studies have reported geographical variations in the circulation of the virulence factors pertaining to the micro-organisms. In Sicily, the cagA gene is present in $52.27 \%$ of strains: in $97 \%$ of the strains, it is associated with the ABC EPIYA motif, and in most, it is associated with the presence of the $\operatorname{sil} 1 \mathrm{~m} 1 \mathrm{vacA}$ allele.

In this study, the rate of $H$. pylori resistance to clarithromycin was high, occurring in $27 \%$ of the cases. The most frequent point mutation in the peptidyl transferase loop region of the $23 S$ rRNA gene was A2143G in $83 \%$ of resistant strains. These data confirm those reported by Fasciana et al. in a previous study [26].

Table 1 shows clinical information of the total patient sample, including age, gender, symptoms, and infection type, patients infected by $H$. pylori, by EBV or both (coinfected). In addition, we identify four groups according to symptom type: normal gastric mucosa (NGM), active chronic gastritis (GCA), gastric cancer (KG), and MALT lymphoma (ML).

In Table 2, we have summarized the results of our gene analysis. The table shows the percentages of polymorphism of vacA gene, polymorphism IL-1RN, and polymorphism IL-10 (-1082). In addition, in patients where the gene vacA was present, the percentage of those with gene cagA positive and oipA "ON" status is reported.

In Table 3, we have described in detail the four groups according to symptom type, reported in Table 1. For each group, we have reported age, gender, infection type (including patients infected by $H$. pilory, EBV, or both), and polymorphism $v a c A$ type. In patients where $v a c A$ was present, the percentage of those with gene cagA positive and oipA "ON" is indicated. Finally, in the last column, we report the results of univariate and multivariate analysis among groups.

In Table 3, we can observe a significant difference for age ( $p$ value $<0.001$ ); in particular, there was a significantly higher number of elderly patients in the gastric cancer and MALT lymphoma groups, in accordance with Ferlay et al. [1].

As regards the characterization of $H$. pilory strains, evaluated directly on gastric biopsies, the polymorphism s1m1i1 of vacA gene was more frequent in Group ML ( $p$ value $=0.0169$ ), while the polymorphism $s 2 m 2 i 2$ was most frequent in Group NGM ( $p$ value $=0.0359$ ) and less frequent in Group KG ( $p$ value $=0.0276)$. In other words, the polymorphism s1m1il was significantly associated with
TABLE 1: Clinical information: age, gender, symptoms, and infection type in the total patient sample.

\begin{tabular}{lc}
\hline Parameters & Sample data \\
\hline Age & $58.27 \pm 16.26$ \\
Gender & \\
$\quad$ Male & $34.38 \%(33 / 96)$ \\
Female & $65.62 \%(63 / 96)$ \\
Symptoms & \\
NGM & $25.00 \%(24 / 96)$ \\
GCA & $25.00 \%(24 / 96)$ \\
ML & $25.00 \%(24 / 96)$ \\
KG & $25.00 \%(24 / 96)$ \\
Analysis with PCR & \\
Not infected & $42.71 \%(41 / 96)$ \\
Infected by HP & $45.83 \%(44 / 96)$ \\
Infected by EBV & $38.54 \%(37 / 96)$ \\
Coinfected & $27.08 \%(26 / 96)$ \\
\hline
\end{tabular}

$\mathrm{NGM}=$ normal gastric mucosa; $\mathrm{GCA}=$ active chronic gastritis; $\mathrm{KG}=$ gastric cancer; $\mathrm{ML}=\mathrm{MALT}$ lymphoma; $\mathrm{HP}=H$. pylori coinfected $=$ patients with $H P$ and $E B V$.

TABLe 2: Gene analysis of our sample data.

\begin{tabular}{lc}
\hline Parameters & Sample data \\
\hline Polymorphism of gene $v a c A$ & \\
s1m1-m2i1 & $2.27 \%(1 / 44)$ \\
s1m2i2 & $4.55 \%(2 / 44)$ \\
s1m2i1 & $6.82 \%(3 / 44)$ \\
s1m1i1 & $40.91 \%(18 / 44)$ \\
s2m2i2 & $45.45 \%(20 / 44)$ \\
Gene cagA $\left(^{\dagger}\right)$ & \\
Negative & $47.73 \%(21 / 44)$ \\
Positive & $52.27 \%(23 / 44)$ \\
Gene oipA $\left(^{\dagger}\right)$ & \\
"OFF" & $47.73 \%(21 / 44)$ \\
"ON" & $52.27 \%(23 / 44)$ \\
Polymorphism IL-1RN & \\
$1 / 1$ & $56.35 \%(54 / 96)$ \\
$1 / 2$ & $21.88 \%(21 / 96)$ \\
$2 / 2$ & $18.75(18 / 96)$ \\
$1 / 3$ & $2.08 \%(2 / 96)$ \\
$4 / 4$ & $1.04 \%(1 / 96)$ \\
Polymorphism IL-10 (-1082) & \\
AA & $47.92 \%(46 / 96)$ \\
AG & $29.17 \%(28 / 96)$ \\
GG & $22.92 \%(22 / 96)$ \\
H. pylori resistant & $27.27 \%(12 / 44)$ \\
H. pylori sensible & $72.73 \%(32 / 44)$ \\
\hline
\end{tabular}

$\mathrm{HP}=H$. pylori; $\mathrm{GCNA}=$ inactive chronic gastritis; $\mathrm{GCA}=$ active chronic gastritis; $\mathrm{KG}=$ gastric cancer; $\mathrm{ML}=\mathrm{MALT}$ lymphoma; ${ }^{\dagger}$ cases where gene vacA was present.

patients with MALT lymphoma, while the polymorphism $s 2 m 2 i 2$ was significantly associated with patients with inactive chronic gastritis.

In addition, the patients positive for $\operatorname{cag} A$ gene were more frequently those affected by gastric cancer $(p$ value $=0.0198)$ and less frequently those with inactive chronic gastritis compared to patients with other diseases $(p$ value $=0.0130)$. A similar situation was found for the oipA gene. Patients with oipA gene and "ON" status were more frequently those with 
TABLE 3: Characteristics of the groups: normal gastric mucosa (NGM), active chronic gastritis (GCA), gastric cancer (KG), and MALT lymphoma (ML). Results of univariate and multivariate analysis among groups.

\begin{tabular}{|c|c|c|c|c|c|}
\hline Parameters & Group NGM & Group GCA & Group KG & Group ML & Univariate and multivariate analysis \\
\hline Age & $46.58 \pm 14.74$ & $49.04 \pm 16.83$ & $69.88 \pm 8.68$ & $67.58 \pm 6.24$ & $\begin{aligned} p<0.001(\mathrm{~A}) \\
\mathrm{NGM}<\mathrm{KG}, p<0.05^{*}(\mathrm{Sh}) \\
\mathrm{NGM}<\mathrm{ML}, p<0.05^{*}(\mathrm{Sh}) \\
\mathrm{GCA}<\mathrm{KG}, p<0.05^{*}(\mathrm{Sh}) \\
\mathrm{GCA}<\mathrm{ML}, p<0.05^{*}(\mathrm{Sh}) \\
\mathrm{NGM}<\mathrm{GCA}, p>0.05(\mathrm{Sh}) \\
\mathrm{ML}<\mathrm{KG}, p>0.05(\mathrm{Sh})\end{aligned}$ \\
\hline \multicolumn{6}{|l|}{ Gender } \\
\hline $\begin{array}{l}\text { Male } \\
\text { Female }\end{array}$ & $\begin{array}{l}33.33 \%(8 / 24) \\
66.67 \%(16 / 24)\end{array}$ & $\begin{array}{l}37.50 \%(9 / 24) \\
62.50 \%(15 / 24)\end{array}$ & $\begin{array}{l}33.33 \%(8 / 24) \\
66.67 \%(16 / 24)\end{array}$ & $\begin{array}{l}33.33 \%(8 / 24) \\
66.67 \%(16 / 24)\end{array}$ & $\begin{array}{l}p=0.987(\mathrm{C}) \\
p=0.987(\mathrm{C})\end{array}$ \\
\hline $\begin{array}{l}\text { Analysis with PCR } \\
\text { Not infected } \\
\text { Infected by HP } \\
\text { Infected by EBV } \\
\text { Coinfected } \\
\end{array}$ & $\begin{array}{l}50.00 \%(12 / 24) \\
45.83 \%(11 / 24) \\
20.83 \%(5 / 24) \\
16.67 \%(4 / 24)\end{array}$ & $\begin{array}{l}45.83 \%(11 / 24) \\
41.67 \%(10 / 24) \\
41.67 \%(10 / 24) \\
29.17 \%(7 / 24)\end{array}$ & $\begin{array}{c}33.33 \%(8 / 24) \\
50.00 \%(12 / 24) \\
54.17 \%(13 / 24) \\
37.50 \%(9 / 24)\end{array}$ & $\begin{array}{l}41.67 \%(10 / 24) \\
45.83 \%(11 / 24) \\
37.50 \%(9 / 24) \\
25.00 \%(6 / 24)\end{array}$ & $\begin{array}{l}p=0.987(\mathrm{C}) \\
p=0.953(\mathrm{C}) \\
p=0.124(\mathrm{C}) \\
p=0.433(\mathrm{C})\end{array}$ \\
\hline \multicolumn{6}{|l|}{ Polymorphism vacA } \\
\hline s1m1i1 & $9.09 \%(1 / 11)$ & $10.00 \%(1 / 10)$ & $58.33 \%(7 / 12)$ & $81.82 \%(9 / 11)$ & $\begin{array}{c}p<0.0001(\mathrm{C})^{*} \\
\mathrm{ML}, p=0.0169(\mathrm{Z})^{* *}\end{array}$ \\
\hline $\begin{array}{l}s 1 m 2 i 1 \\
s 1 m 2 i 2\end{array}$ & $\begin{array}{l}0.00 \%(0 / 11) \\
9.09 \%(1 / 11)\end{array}$ & $\begin{array}{l}10.00 \%(1 / 10) \\
0.00 \%(0 / 10)\end{array}$ & $\begin{array}{l}16.67 \%(2 / 12) \\
8.33 \%(1 / 12)\end{array}$ & $\begin{array}{l}0.00 \%(0 / 11) \\
0.00 \%(0 / 11)\end{array}$ & $\begin{array}{c}p=0.308(\mathrm{C}) \\
p=0.589(\mathrm{C}) \\
p<0.0001(\mathrm{C})^{*}\end{array}$ \\
\hline$s 2 m 2 i 2$ & $81.82 \%(9 / 11)$ & $80.00 \%(8 / 10)$ & $8.33 \%(1 / 12)$ & $18.18 \%(2 / 11)$ & $\begin{array}{l}\mathrm{NGM}, p=0.0359(Z)^{* *} \\
\mathrm{KG}, p=0.0276(\mathrm{Z})^{* * *}\end{array}$ \\
\hline$s 1 m 1-m 2 i 1$ & $0.00 \%(0 / 11)$ & $0.00 \%(0 / 10)$ & $8.33 \%(1 / 12)$ & $0.00 \%(0 / 11)$ & $p=0.435(\mathrm{C})$ \\
\hline \multicolumn{6}{|l|}{ Gene $\operatorname{cag} A\left(^{\dagger}\right)$} \\
\hline Negative & $90.91 \%(10 / 11)$ & $80.00 \%(8 / 10)$ & $8.33 \%(1 / 12)$ & $18.18 \%(2 / 11)$ & $\begin{array}{c}p<0.0001(\mathrm{C})^{*} \\
\mathrm{NGM}, p=0.0130(\mathrm{Z})^{* *} \\
\mathrm{KG}, p=0.0198(\mathrm{Z})^{* * *} \\
p<0.0001(\mathrm{C})^{*}\end{array}$ \\
\hline Positive & $9.09 \%(1 / 11)$ & $20.00 \%(2 / 10)$ & $91.67 \%(11 / 12)$ & $81.82 \%(9 / 11)$ & $\begin{array}{c}\mathrm{KG}, p=0.0198(Z)^{* *} \\
\mathrm{NGM}, p=0.0130(Z)^{* * *}\end{array}$ \\
\hline \multicolumn{6}{|l|}{ Gene oipA $\left(^{\dagger}\right)$} \\
\hline "OFF" & $90.91 \%(10 / 11)$ & $80.00 \%(8 / 10)$ & $8.33 \%(1 / 12)$ & $18.18 \%(2 / 11)$ & $\begin{array}{c}p<0.0001(\mathrm{C})^{*} \\
\mathrm{NGM}, p=0.0130(\mathrm{Z})^{* *} \\
\mathrm{KG}, p=0.0198(\mathrm{Z})^{* * *} \\
p<0.0001(\mathrm{C})^{*}\end{array}$ \\
\hline “ON" & $9.09 \%(1 / 11)$ & $20.00 \%(2 / 10)$ & $91.67 \%(11 / 12)$ & $81.82 \%(9 / 11)$ & $\begin{array}{c}\mathrm{KG}, p=0.0198(Z)^{* *} \\
\mathrm{NGM}, p=0.0130(Z)^{* * *}\end{array}$ \\
\hline
\end{tabular}

" significant test; ${ }^{* *}$ significant most frequent; ${ }^{* * *}$ significant less frequent; $A=$ multicomparison ANOVA test; $S h=$ post hoc Scheffé's test for pairwise comparison; $C=$ multicomparison chi-square test; $Z=Z$-test; $H P=H$. pylori; coinfected = patients with $H P$ and $E B V$; NGM=normal gastric mucosa; $\mathrm{GCA}=$ active chronic gastritis; $\mathrm{KG}=$ gastric cancer; $\mathrm{ML}=\mathrm{MALT}$ lymphoma; ${ }^{\dagger}=$ cases where gene vacA was present; $p=p$ value.

gastric cancer $(p$ value $=0.0198)$ and less frequently those with inactive chronic gastritis $(p$ value $=0.0130)$.

Regarding number of CT repeats, the most prevalent in the "ON" frame status had six CT repeats. This was found to be the case in other studies $[26,30]$. Among the out-frame status, "OFF" variants, the patterns with eight CT repeats were the most prevalent.

The evidence pointing to the oipA "ON" as a gastric cancer risk factor includes the ability of the bacterium carrying a functional oipA to attach to the gastric epithelial cells and induce inflammation, apoptosis, and a toxic effect on towards cultured gastric epithelial cell lines.

In Table 4, we can see the sequences of signal peptideencoding region of oipA.
Analysis of the $23 S$ rRNA gene demonstrated that 32 (73\%) patients were infected with $H$. pylori-susceptible strains and the remaining $12(27 \%)$ with resistant strains (Table 2). The predominant point mutation observed among the $12 \mathrm{H}$. pylori resistant strains was A2143G in 10 cases (83 $\%)$ and $A 2142 \mathrm{G}$ in 2 cases (17\%).

In Table 5, we report the frequency of polymorphism IL1RN and IL-10 loci for every group. In the last column, we report the results of univariate and multivariate analysis performed among the groups.

Table 5 shows that there was only one significant association between polymorphism IL-1RN and gastric disease. Particularly, patients with polymorphism IL-1RN type $1 / 2$ were significantly less frequent in the ML Group ( $p$ value $=0.0248$ ). 
TABLE 4: oipA CT repeat patterns.

\begin{tabular}{|c|c|c|}
\hline Sequence of signal peptide-encoding region of oipA & No. CT & No. of strains \\
\hline \multicolumn{3}{|l|}{ OFF status } \\
\hline ATGAAAAAAGCTCTCTTA..........СTCTCTCTСTCTCTCTCTCGTT & 9 & 5 \\
\hline ATGAAAAAAGCCCTCTTACTAACTCTCTCTCTCTCTCTCGTTT & 8 & 7 \\
\hline 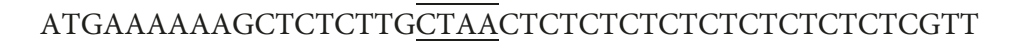 & 10 & 2 \\
\hline ATGAAAAAAGCTCTTTTA........CTCTCTCTCTCTCGTT & 6 & 3 \\
\hline ATGAAAAAAGCTCTCTTACTAACTCTCTCTCTCTCTCGTT & 7 & 2 \\
\hline ATGAAAAAGCTCTCTTA.........СТСTCTCTCTCTCTCGTTCTGG & 7 & 1 \\
\hline ATGAAAAAAGCCCTCTTA.........СTCTCTCTTTCTCTCGTTTT & $4+2$ & 1 \\
\hline Total & & 21 \\
\hline \multicolumn{3}{|l|}{ ON status } \\
\hline ATGAAAAAAGCTCTCTTACTAATTCTCTCTCTCTCGTT & 5 & 4 \\
\hline ATGAAAAAAGCTCTCTTA $\overline{\overline{C T A A}}$ CTCTCTCTCTCTCGTT & 6 & 15 \\
\hline ATGAAAAAAGCCСТCTTA..........СТСТСТСТСТСТСТСТСТСТСТСGT & 11 & 2 \\
\hline ATGAAAAAAGCTCTCTTACTAACT CTCTCTCTCTCTCTCTCGTT & 9 & 1 \\
\hline ATGAAAAAAGCTCTTTTAСТCTCT СТCTCTCTCTCGTT & 8 & 1 \\
\hline Total & & 23 \\
\hline
\end{tabular}

TABLE 5: Frequency of the polymorphisms IL1RN and IL-10 loci. Results of univariate and multivariate analysis among groups.

\begin{tabular}{lccccc}
\hline Parameters & Group NGM & Group GCA & Group KG & Group ML & Univariate and multivariate analysis \\
\hline $\begin{array}{l}\text { Polymorphism IL-1RN } \\
\quad 1 / 1\end{array}$ & $50.00 \%(12 / 24)$ & $62.50 \%(15 / 24)$ & $41.67 \%(10 / 24)$ & $70.83 \%(17 / 24)$ & $0.179(\mathrm{C})$ \\
$1 / 2$ & $29.17 \%(7 / 24)$ & $25.00 \%(6 / 24)$ & $33.33 \%(8 / 24)$ & $0.00 \%(0 / 24)$ & $0.0239(\mathrm{C})^{*}$ \\
$2 / 2$ & $20.83 \%(5 / 24)$ & $8.33 \%(2 / 24)$ & $16.67 \%(4 / 24)$ & $29.17 \%(7 / 24)$ & group ML*** $^{* *}=0.0248(\mathrm{Z})$ \\
$1 / 3$ & $0.00 \%(0 / 24)$ & $4.17 \%(1 / 24)$ & $4.17 \%(1 / 24)$ & $0.00 \%(0 / 24)$ & $0.314(\mathrm{C})$ \\
$4 / 4$ & $0.00 \%(0 / 24)$ & $0.00 \%(0 / 24)$ & $4.17 \%(1 / 24)$ & $0.00 \%(0 / 24)$ & $0.564(\mathrm{C})$ \\
Polymorphism IL-10 (-1082) & & & & $0.387(\mathrm{C})$ \\
AA & $41.67 \%(10 / 24)$ & $45.83 \%(11 / 24)$ & $54.17 \%(13 / 24)$ & $50.00 \%(12 / 24)$ & $0.841(\mathrm{C})$ \\
AG & $33.33 \%(8 / 24)$ & $33.33 \%(8 / 24)$ & $29.17 \%(7 / 24)$ & $20.83 \%(5 / 24)$ & $0.875(\mathrm{C})$ \\
GG & $25.00 \%(6 / 24)$ & $20.83 \%(5 / 24)$ & $16.67 \%(4 / 24)$ & $29.17 \%(7 / 24)$ & $0.768(\mathrm{C})$ \\
\hline
\end{tabular}

*Significant test; ${ }^{* *}$ significant most frequent; ${ }^{* * *}$ significant less frequent; \#= no localized significant modality with significant level $<0.05$; $C=$ multicomparison chi-square test; $Z=Z$-test; $\mathrm{HP}=H$. pylori; $\mathrm{NGM}=$ normal gastric mucosa; $\mathrm{GCA}=$ active chronic gastritis; $\mathrm{KG}=$ gastric cancer; $\mathrm{ML}=$ MALT lymphoma; $p=p$ value.

TABLE 6: Results of univariate and multivariate linear correlation analysis between polymorphism of vacA, IL-1RN and IL-10 with age, gender, H. pylori, EBV, coinfected, and gastric disease.

\begin{tabular}{lcc}
\hline Linear correlation analysis & Univariate analysis & Multivariate analysis \\
\hline & $R(p$ value $)$ & Multiple linear correlation coefficient $=0.149$ \\
Polymorphism IL-1RN/age & $-0.092(0.371)$ & $R_{\text {partial }}=-0.057 ; p$ value $=0.593$ \\
Polymorphism IL-1RN/gender & $-0.038(0.716)$ & $R_{\text {partial }}=-0.013 ; p$ value $=0.905$ \\
Polymorphism IL-1RN/H. pylori & $0.02(0.846)$ & $R_{\text {partial }}=-0.027 ; p$ value $=0.800$ \\
Polymorphism IL-1RN/EBV & $-0.027(0.794)$ & $R_{\text {partial }}=0.052 ; p$ value $=0.622$ \\
Polymorphism IL-1RN/coinfected & $-0.015(0.886)$ & $R_{\text {partial }}=-0.011 ; p$ value $=0.917$ \\
Polymorphism IL-1RN/gastric disease & $-0.097(0.348)$ & $R_{\text {partial }}=-0.107 ; p$ value $=0.314$ \\
& $R(p$ value $)$ & Multiple linear correlation coefficient $=0.215$ \\
Polymorphism IL-10/age & $0.116(0.259)$ & $R_{\text {partial }}=0.106 ; p$ value $=0.316$ \\
Polymorphism IL-10/gender & $-0.142(0.167)$ & $R_{\text {partial }}=-0.125 ; p$ value $=0.237$ \\
Polymorphism IL-10/H. $p y l o r i$ & $0.102(0.322)$ & $R_{\text {partial }}=-0.024 ; p$ value $=0.821$ \\
Polymorphism IL-10/EBV & $0.081(0.430)$ & $R_{\text {partial }}=-0.054 ; p$ value $=0.619$ \\
Polymorphism IL-10/coinfected & $0.101(0.329)$ & $R_{\text {partial }}=0.062 ; p$ value $=0.560$ \\
Polymorphism IL-10/gastric disease & $0.061(0.552)$ & $R_{\text {partial }}=0.027 ; p$ value $=0.797$
\end{tabular}

*Significant test; $R=$ Pearson's linear correlation coefficient; $R_{\text {partial }}=$ the partial correlation coefficient is the coefficient of correlation of the variable with the dependent variable, adjusted for the effect of the other variables in the mode; coinfected = patients with $H$. pylori and $E B V$. 
These results, in accordance with other reports, do not seem to attribute any particular role to proinflammatory or anti-inflammatory cytokine genotypes in gastric disease susceptibility [28].

Finally, in Table 6, we report the results of univariate and multivariate linear correlation analyses between polymorphisms IL-1RN and IL-10, with the independent variables age, gender, $H$. pylori infection, EBV infection, coinfection, and gastric disease. In this case, no correlations were found.

\section{Conclusions}

We can conclude that the various factors that can be involved in cancer development are very complex. A limitation of this study was the limited number of patients with the various gastric diseases. Therefore, further investigations are necessary to fully correlate the role of coinfection in gastric diseases in the Sicilian population. In addition, coinfection should be evaluated at an early age and in children with an increased risk of presenting more serious lesions later in life.

\section{Disclosure}

An earlier version of this manuscript was presented as an abstract at the $46^{\text {th }}$ Congress of the Italian Society of Microbiology, September $26^{\text {th }}-29^{\text {th }}, 2018$.

\section{Conflicts of Interest}

The authors declare that they have no conflicts of interest.

\section{Authors' Contributions}

TF, AG, LS, and PDC conceived and designed the study. TF, AG, and NS managed the conduction of the study. TF, CM, GC, SC, and MS performed molecular analysis. NS and CG performed statistical analysis and drafted the manuscript. TF, AG, GC, and CG analyzed the data and drafted the manuscript. All authors read and approved the final manuscript.

\section{References}

[1] J. Ferlay, I. Soerjomataram, R. Dikshit et al., "Cancer incidence and mortality worldwide: sources, methods and major patterns in GLOBOCAN 2012," International Journal of Cancer, vol. 136, no. 5, pp. E359-E386, 2015.

[2] J. M. Noto, J. A. Gaddy, J. Y. Lee et al., "Iron deficiency accelerates Helicobacter pylori-induced carcinogenesis in rodents and humans," Journal of Clinical Investigation, vol. 123, no. 1, pp. 479-492, 2013.

[3] D. Iwakiri and K. Takada, "Epstein-Barr virus and gastric cancers," in Epstein-Barr Virus, E. S. Roberston, Ed., Caister Academic Press, Norfolk, VA, USA, 2005.

[4] H. Tanaka, M. Yoshida, S. Nishiumi et al., "The CagA protein of Helicobacter pylori suppresses the functions of dendritic cell in mice," Archives of Biochemistry and Biophysics, vol. 498, no. 1, pp. 35-42, 2010.

[5] S. L. Palframan, T. Kwok, and K. Gabriel, "Vacuolating cytotoxin A (VacA), a key toxin for Helicobacter pylori pathogenesis," Frontiers in Cellular and Infection Microbiology, vol. 2, p. 92, 2012.

[6] A. T. Franco, E. Johnston, U. Krishna et al., "Regulation of gastric carcinogenesis by Helicobacter pylori virulence factors," Cancer Research, vol. 68, no. 2, pp. 379-387, 2008.

[7] T. L. Testerman and J. Morris, "Beyond the stomach: an updated view of Helicobacter pylori pathogenesis, diagnosis, and treatment," World Journal of Gastroenterology, vol. 20, no. 36, pp. 12781-12808, 2014.

[8] Y. Yamaoka, D. H. Kwon, and D. Y. Graham, "A Mr 34,000 proinflammatory outer membrane protein (oipA) of Helicobacter pylori," Proceedings of the National Academy of Sciences, vol. 97, no. 13, pp. 7533-7538, 2000.

[9] O. L. Hatton, A. Arnold-Harris, S. Schaffert, S. M. Krams, and O. M. Martinez, "The interplay between Epstein Barr virus and B lymphocytes: implications for infection, immunity, and disease," Immunologic Research, vol. 58, no. 2-3, pp. 268-276, 2014.

[10] W. K. K. Wu, J. Yu, M. T. V. Chan, K. F. To, and A. S. L. Cheng, "Combinatorial epigenetic deregulation by Helicobacter pylori and Epstein-Barr virus infections in gastric tumorigenesis," The Journal of Pathology, vol. 239, no. 3, pp. 245-249, 2016.

[11] A. Shinozaki-Ushiku, A. Kunita, M. Isogai et al., "Profiling of virus-encoded microRNAs in Epstein-Barr virus-associated gastric carcinoma and their roles in gastric carcinogenesis," Journal of Virology, vol. 89, no. 10, pp. 5581-5591, 2015.

[12] M. G. Cárdenas-Mondragón, J. Torres, L. Flores-Luna et al., "Case-control study of Epstein-Barr virus and Helicobacter pylori serology in Latin American patients with gastric disease," British Journal of Cancer, vol. 112, no. 12, pp. 18661873, 2015.

[13] J. L. Ryan, Y.-J. Shen, D. R. Morgan et al., "Epstein-Barr virus infection is common in inflamed gastrointestinal mucosa," Digestive Diseases and Sciences, vol. 57, no. 7, pp. 1887-1898, 2012.

[14] A. Morales-Sánchez and E. Fuentes-Pananá, "Human viruses and cancer," Viruses, vol. 6, no. 10, pp. 4047-4079, 2014.

[15] S. Mishra, "Is Helicobacter pylori good or bad?," European Journal of Clinical Microbiology \& Infectious Diseases, vol. 32, no. 3, pp. 301-304, 2013.

[16] H. C. Leggett, C. K. Cornwallis, A. Buckling, and S. A. West, "Growth rate, transmission mode and virulence in human pathogens," Philosophical Transactions of the Royal Society B: Biological Sciences, vol. 372, no. 1719, article 20160094, 2017.

[17] I. B. Ramis, J. S. Vianna, C. V. Gonçalves, A. von Groll, O. A. Dellagostin, and P. E. A. da Silva, "Polymorphisms of the IL6 , IL- 8 and IL-10 genes and the risk of gastric pathology in patients infected with Helicobacter pylori," Journal of Microbiology, Immunology and Infection, vol. 50, no. 2, pp. 153-159, 2017.

[18] J. M. Kang, N. Kim, D. H. Lee et al., "The effects of genetic polymorphisms of IL-6, IL-8, and IL-10 on Helicobacter pylori-induced gastroduodenal diseases in Korea," Journal of Clinical Gastroenterology, vol. 43, no. 5, pp. 420-428, 2009.

[19] P. Di Carlo, M. Trizzino, L. Titone et al., "Unusual MRI findings in an immunocompetent patient with EBV encephalitis: a case report," BMC Medical Imaging, vol. 11, no. 1, p. 6, 2011.

[20] A. Giardina, A. Rizzo, A. Ferrante, G. Capra, G. Triolo, and F. Ciccia, "Giant cell arteritis associated with chronic active Epstein Barr virus infection," Reumatismo, vol. 65, no. 1, pp. 36-39, 2013.

[21] E. G. Panayotopoulou, D. N. Sgouras, K. Papadakos et al., "Strategy to characterize the number and type of repeating EPIYA phosphorylation motifs in the carboxyl terminus of 
CagA protein in Helicobacter pylori clinical isolates," Journal of Clinical Microbiology, vol. 45, no. 2, pp. 488-495, 2007.

[22] J. C. Atherton, P. Cao, R. M. Peek Jr., M. K. Tummuru, M. J. Blaser, and T. L. Cover, "Mosaicism in vacuolating cytotoxin alleles of Helicobacter pylori: association of specific vacA types with cytotoxin production and peptic ulceration," Journal of Biological Chemistry, vol. 270, no. 30, pp. 1777117777, 1995.

[23] J. L. Rhead, D. P. Letley, M. Mohammadi et al., "A new Helicobacter pylori vacuolating cytotoxin determinant, the intermediate region, is associated with gastric cancer," Gastroenterology, vol. 133, no. 3, pp. 926-36, 2007.

[24] Y. Yamaoka, S. Kikuchi, H. M T el-Zimaity, O. Gutierrez, M. S. Osato, and D. Graham, "Importance of Helicobacter pylori oipA in clinical presentation, gastric inflammation, and mucosal interleukin 8 production," Gastroenterology, vol. 123 (2), pp. 414-424, 2002.

[25] A. Chiarini, C. Calà, C. Bonura et al., "Prevalence of virulenceassociated genotypes of Helicobacter pylori and correlation with severity of gastric pathology in patients from western Sicily, Italy," European Journal of Clinical Microbiology \& Infectious Diseases, vol. 28, no. 5, pp. 437-446, 2009.

[26] T. Fasciana, G. Scarpulla, A. Giammanco et al., "Resistance to clarithromycin and genotypes in Helicobacter pylori strains isolated in Sicily," Journal of Medical Microbiology, vol. 64, no. 11, pp. 1408-1414, 2015.

[27] R. Rad, C. Prinz, B. Neu et al., "Synergistic effect of Helicobacter pylori virulence factors and interleukin-1 polymorphisms for the development of severe histological changes in the gastric mucosa," Journal of Infectious Diseases, vol. 188, no. 2, pp. 272-815, 2003.

[28] G. I. Forte, C. Calà, L. Scola et al., "Role of environmental and genetic factor interaction in age-related disease development: the gastric cancer paradigm," Rejuvenation Research, vol. 11, no. 2, pp. 509-512, 2008.

[29] A. Crivello, A. Giacalone, M. Vaglica et al., "Regulatory cytokine gene polymorphisms and risk of colorectal carcinoma," Annals of the New York Academy of Sciences, vol. 1089, no. 1, pp. 98-103, 2006.

[30] T. Fasciana, G. Capra, C. Calà et al., "Helicobacter pylori and Epstein Barr co-infection in gastric disease," Pharmacology Online, vol. 1, pp. 73-82, 2017. 


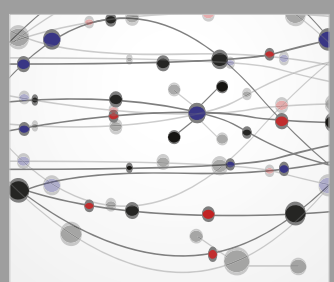

The Scientific World Journal
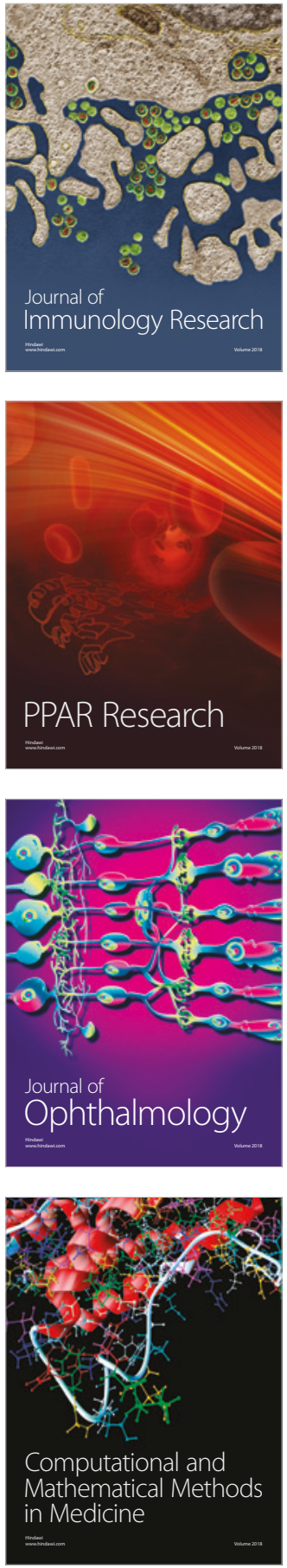

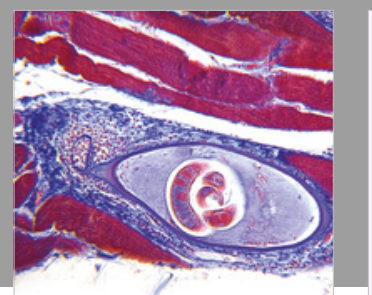

Gastroenterology Research and Practice

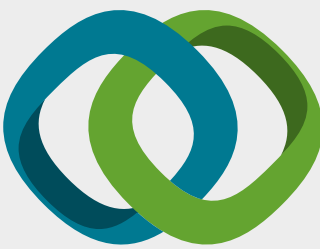

\section{Hindawi}

Submit your manuscripts at

www.hindawi.com
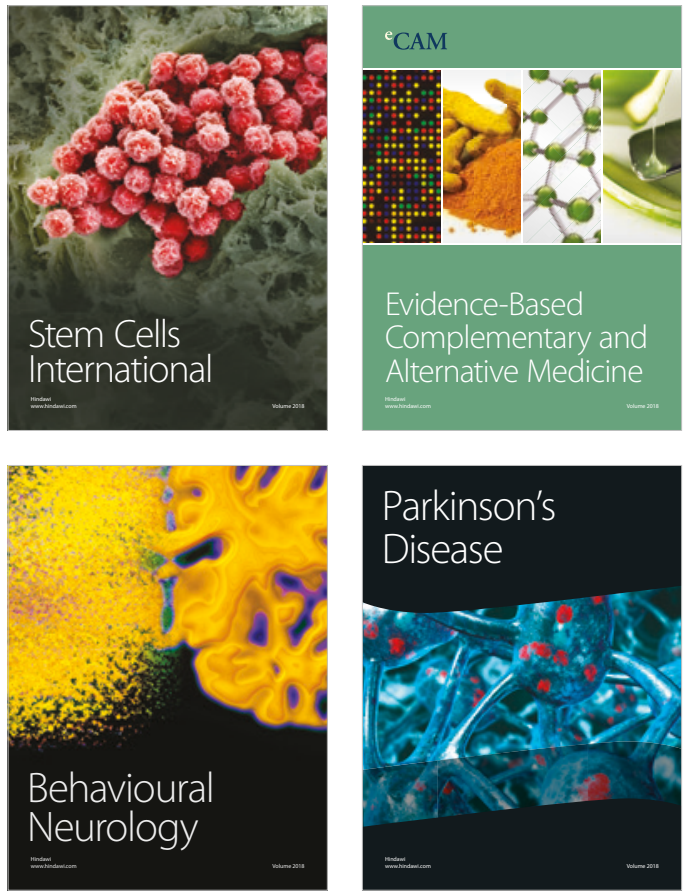

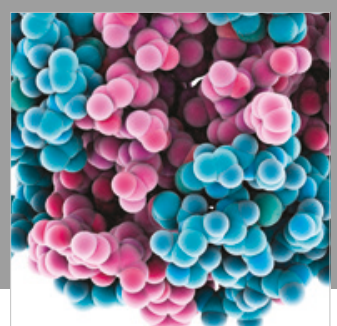

ournal of

Diabetes Research

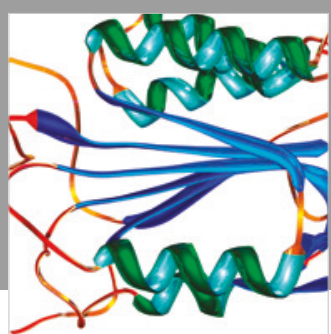

Disease Markers
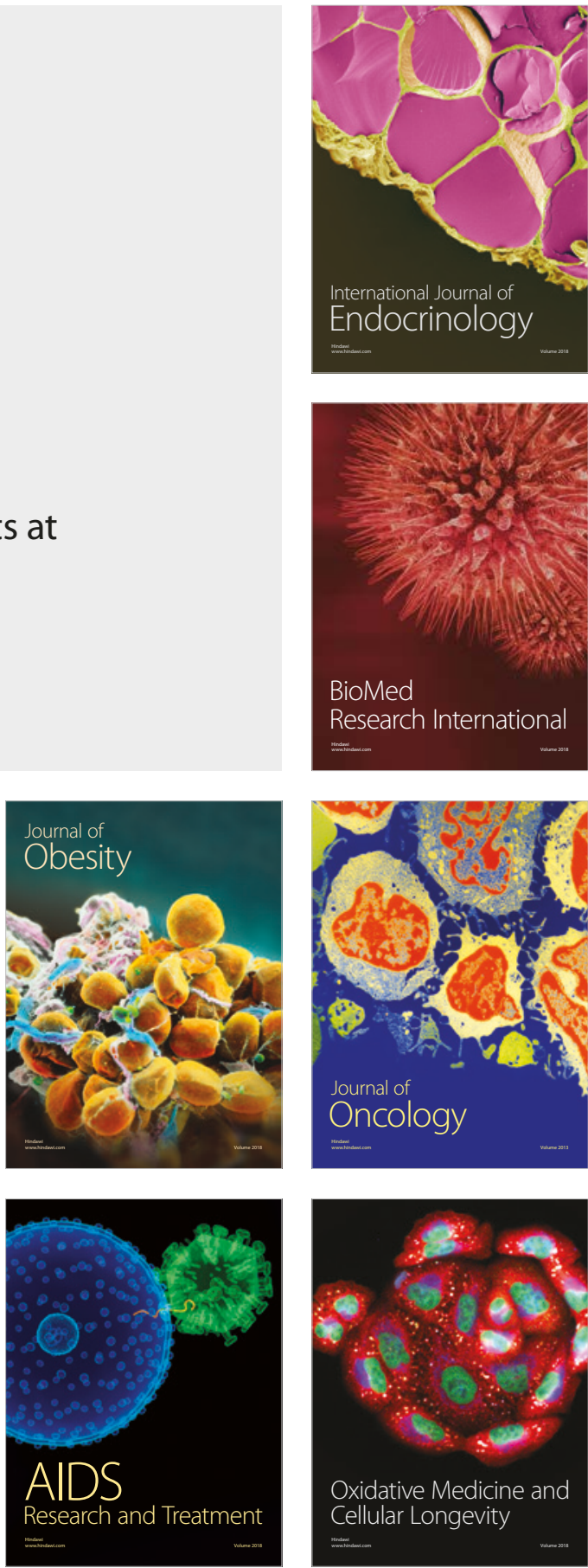